\title{
Isonitrilos, Compostos Versáteis em Sistemas Biológicos e Orgânicos*
}

\author{
RUDOLF HERRMANNa E ARMANO J.L. POMBEIRO b
}

\begin{abstract}
Apresentam-se a descoberta e a ocorrência natural de isonitrilos (isocianetos), a sua síntese e reactividade versátil (quer em sistemas organometálicos quer orgânicos, os primeiros envolvendo a activação de isonitrilos por coordenação a um centro metálico) em particular orientada com vista à modelagem da função da nitrogenase e ao desenvolvimento de aplicações em síntese orgânica (e.g., via reacções estereo-selectivas de condensação de

multicomponentes com formação de peptídeos, $\beta$-lactamas e outros heterociclos, nomeadamente com interesse farmacológico), e de potencial significado tecnológico (e.g., sínteses de polímeros

funcionalizados e imobilização de enzimas).
\end{abstract}

\section{1 - INTRODUÇÃO}

No ano de 1859, W. Lieke publicou um artigo [1] descrevendo várias observações sobre a reacção entre o brometo de alilo e o cianeto de prata (equação 1). Obteve um produto que considerou ser um nitrilo (cianeto) e descreveu do modo seguinte: "O cianeto alílico tem um cheiro penetrante, extremamente desagradável; abrir um frasco que o contenha é suficiente para infestar o ar da sala por uns dias; por isso era preciso continuar todos os trabalhos ao ar livre. (...) Não tive material para mais ensaios e não podia sintetizar maiores quantidades do cianeto alílico, devido às queixas dos vizinhos do laboratório de todos os lados".

Observações semelhantes foram registadas também por Meyer [2], mas somente no ano de 1867, A. Gautier [3] e A.W. Hofmann [4] descobriram, simultânea e independentemente, que os produtos malcheirosos não são os nitrilos esperados, mas sim isómeros, que Gautier designou por isonitrilos ou isocianetos. O cheiro "horrivel" é uma característica de quase todos os isocianetos voláteis, e ainda hoje não existe uma explicação para a intensidade e a qualidade de tal aroma.
Gautier foi menos receososo das queixas dos seus vizinhos do que os outros investigadores e continuou a trabalhar com estes produtos. Considerou os isonitrilos como homólogos do ácido cianídrico (cianeto de hidrogénio), e sugeriu a fórmula (a) para o etilisocianeto, indicando que é o átomo de azoto que está ligado ao grupo etílico, enquanto que, no nitrilo correspondente, a ligação é feita através do carbono. Hoje prefere-se a formulação (b), que reflecte a distribuição electrónica na molécula e a distância curta entre os átomos de carbono e azoto correspondente a uma ligação tripla.

O método de síntese de Lieke e Gautier consiste na alquilação de cianeto, que é um anião ambidentado que pode ser alquilado quer no átomo de carbono quer no de azoto, com formação usual de uma mistura de nitrilo e isonitrilo, de separação difícil. Inicialmente não era esperada a possibilidade da obtenção de isómeros, dado que a protonação de cianeto resulta num só produto, com o hidrogénio ligado ao carbono, o que corresponde, no caso da alquilação, à formação do nitrilo. A estabilidade termodinâmica dos nitrilos é quase sempre superior à dos isonitrilos os quais, por aquecimento a temperatu- ras elevadas, designadamente por pirólise (temperaturas de ca. $450^{\circ} \mathrm{C} \mathrm{em}$ alto vácuo [5], isomerizam nos primeiros (equação 2). No caso de vários isonitrilos quirais, a quiralidade é transferida ao nitrilo, com retenção, indicando que o mecanismo neste caso não envolve quebra da ligação $\mathrm{R}-\mathrm{N}$ (formação de radicais), mas sim uma migração intramolecular do grupo quiral (equação 3). Um caso particular são os homólogos dos isonitrilos alquílicos que têm o grupo $\mathrm{CN}$ ligado a um átomo de silício. Inicialmente, foram considerados como isonitrilos [6], mas hoje sabe-se, por espectrometria de RMN [7], espectroscopia de IV [8] e microondas [9], que envolvem um equilíbrio entre os isómeros cianeto e isocianeto (equação 4), com um teor de isocianeto que não ultrapassa os $0,3 \%$ embora podendo aumentar um pouco a temperaturas elevadas [10].

Como a síntese de isonitrilos por alquilação de cianeto quase sempre resulta em misturas com os nitrilos correspondentes, foram investigados métodos alternativos na sua preparação. Assim, A.W. Hofmann [4] obteve isonitrilos a partir de aminas primárias, tratando-as com clorofórmio e hidróxido de sódio, mas este processo era habitualmente de baixo

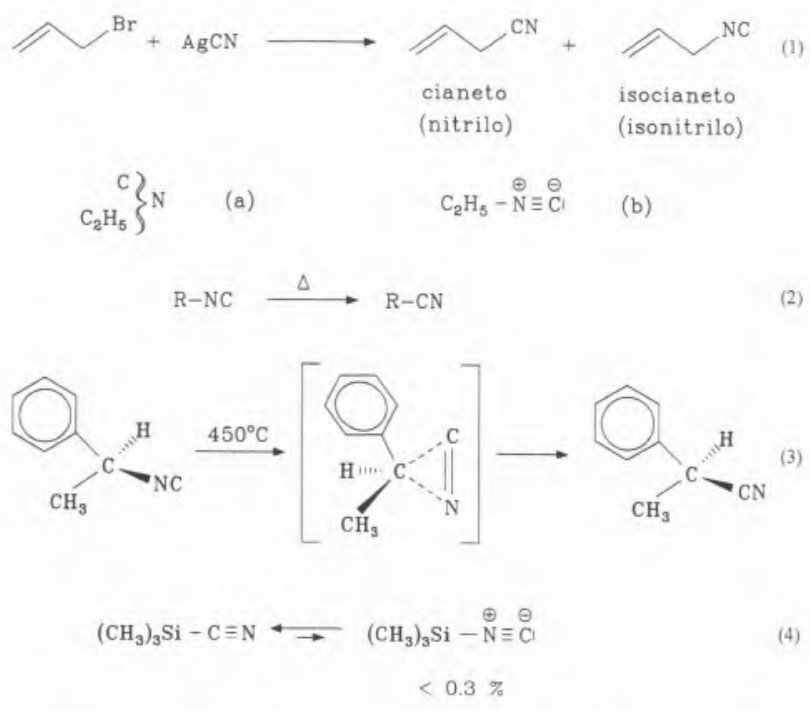

Figura 1- Descoberta dos isocianetos (isonitrilos) por Lieke, no ano de 1859 (1). Formulação de Gautier (a), indicando a ligação $\mathrm{C}-\mathrm{N}-\mathrm{C}_{2} \mathrm{H}_{5}$, e formulação actual (b). Rearranjo de isocianetos a cianetos (nitrilos) (2), e respectivo mecanismo no caso de um isocianeto quiral com retenção da configuração (3). Equilíbrio entre o trimetilsililisocianeto e a forma nitrilica, com contribuição do primeiro inferior a $0,3 \%(4)$, 


$$
\begin{aligned}
& \mathrm{CHCl}_{3} \frac{\mathrm{NBu}_{4} \mathrm{Cl}}{\substack{\mathrm{NaOH},-\mathrm{NaCl} \\
-\mathrm{H}_{2} \mathrm{O}}} \underset{\begin{array}{l}
\text { dicloro- } \\
\text { carbeno }
\end{array}}{\mathrm{CCl}_{2}} \stackrel{+2 \mathrm{R}-\mathrm{NH}_{2}}{-2 \mathrm{HCl}} \mathrm{R}-\stackrel{\oplus}{\mathrm{N}} \equiv \stackrel{\ominus}{\mathrm{C}} \\
& \mathrm{R}-\mathrm{NH}_{2} \underset{\mathrm{HCO}_{2} \mathrm{Et}}{\stackrel{\mathrm{HCO}_{2} \mathrm{H} \text { ou }}{\longrightarrow}} \begin{array}{l}
\mathrm{R}-\mathrm{NH}-\mathrm{CHO} \\
\text { formamida }
\end{array} \frac{\begin{array}{l}
-\mathrm{H}_{2} \mathrm{O} \\
\text { (e.g. } \mathrm{POCl}_{3}
\end{array}}{\left./ \mathrm{HN}^{i} \mathrm{Pr}_{2}\right)} \mathrm{R}-\stackrel{\oplus}{\mathrm{N}} \equiv \stackrel{\ominus}{\mathrm{Cl}}
\end{aligned}
$$

Figura 2 - Preparação de isocianetos a partir de aminas por reaç̧ão com diclorocarbeno (método de Hoffmann e Gokel, recorrendo a transferência de fase) (5), e método geral de Ugi de desidratação de formamidas (6). rendimento. Demorou mais de um século a descoberta de uma variação do processo original, recorrendo à catálise de transferência de fase, com rendimentos razoáveis [11]. O mecanismo consiste na formação de diclorocarbeno por reacção do hidróxido com clorofórmio, o qual depois reage com a amina, libertando-se $\mathrm{HCl}$ no passo final (equação 5).

Após se ter iniciado com as investigações interessantes de Gautier, a química dos isonitrilos desenvolveu-se pouco durante quase 90 anos, parcialmente por causa do cheiro, mas sem dúvida também porque não existia um método conveniente de síntese. O interesse industrial nos isonitrilos acordou a "bela adormecida", resultando num novo processo sintético, investigado sistematicamente por I. Ugi e colaboradores [12], que consiste na desidratação de formamidas (equação 6). Trata-se de um protodas as formamidas, e bastante flexível, podendo ser utilizados diversos agentes desidratantes, tais como o fosgénio ou o difosgénio, cloretos sulfonílicos, etc. Para uso laboratorial, o método mais conveniente consiste provavelmente na desidratação por $\mathrm{POCl}_{3}$ em combinação com diisopropilamina como base [13].

\section{2 - ISOCIANETOS COMO PRODUTOS NATURAIS E SUAS APLICAÇÕES FARMACOLÓGICAS}

Considerando a sua via química de síntese e as semelhanças entre os isonitrilos e o HCN esperava-se uma alta toxicidade para estas espécies, pelo que foi surpreendente a descoberta, como produto natural, de um cesso muito geral, aplicável a quase isocianeto, chamado xantocilina, existente no fungo Penicillum notatum [14]. Menos inesperadas foram então as propriedades antibióticas deste composto, o qual provavelmente faz parte do sistema de defesa do fungo contra diversos micróbios. Entretanto, foram isolados vários isonitrilos de outros microorganismos, em particular a tricoviridina (da Trichoderma $s p$ ), e o hapalindolo A (de uma alga terrestre, Hapalasiphon fontinalis) [15]. Mas a maior parte dos isonitrilos naturais encontra-se em animais marítimos, como esponjas (Porifera) [16], apresentando estruturas muito variadas, tais como o adociano (de Amphimedon $s p$.), o grupo dos caliinolos (de Acanthella sp.), e os pupuqueananos (de Ciocalypta $s p$.).

Embora as esponjas utilizem os isonitrilos e outros compostos venenosos como defesa contra animais carnívoros (provavelmente o mau sabor é já suficiente para desanimálos), existem certos moluscos que não só são capazes de ingerir as esponjas, mas também de incorporar os isonitrilos e utilizá-los para a sua própria defesa. Alguns isonitrilos foram primeiramente isolados de moluscos (como a Phylida varicosa no caso dos pupuqueananos) os quais, só por acaso, foram observados a alimentar-se das esponjas que, na realidade, constituem a primeira fonte destes compostos. A esponja e o molusco formam, assim, um sistema ecológico marítimo, envolvendo uma forma de guerra com armas químicas, o que constitui uma associação fascinante entre biologia e a química [17].

Uma questão fundamental a esclarecer é a forma como os seres vivos são capazes de produzir isonitrilos, isto é, o problema da sua biosíntese. Parece óbvio que, nos casos da xantocilina e do hapalindolo, os aminoácidos tirosina e triptofana constituem a matéria prima, uma vez que a sua estrutura ainda é claramente visível nos produtos. Porém, é já muito menos óbvio que também seja a tirosina o composto de partida no caso da tricoviridina [18]. De um modo geral, os isonitrilos marítimos são derivados de terpenos, mas a origem do próprio grupo
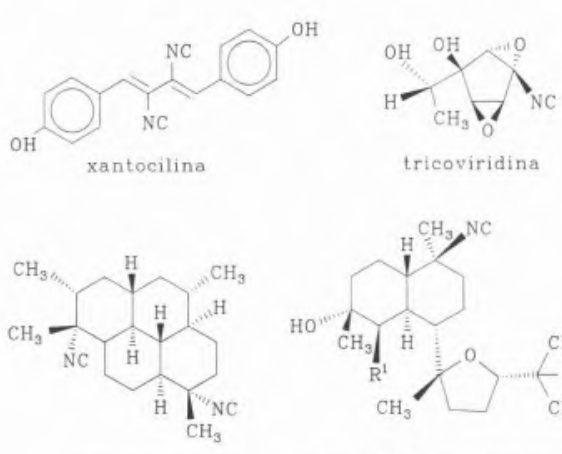

adociano

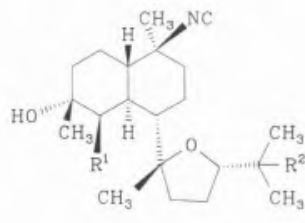

$\mathrm{R}^{1}=\mathrm{R}^{2}=\mathrm{NC}$ : caliinolo $\mathrm{F}$ $\mathrm{R}^{1}=\mathrm{NC}, \mathrm{R}^{2}=\mathrm{Cl}$ : calininolo $\mathrm{B}$ $\mathrm{R}^{1}=\mathrm{Cl}, \mathrm{R}^{2}=\mathrm{NC}$ : calininolo $\mathrm{D}$

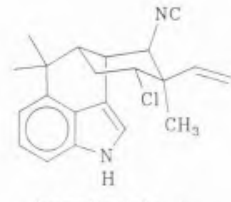

hapalindolo $A$

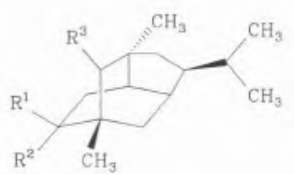

pupuqueananos

$\mathrm{R}^{1}=\mathrm{NC}, \mathrm{R}^{2}=\mathrm{R}^{3}=\mathrm{H}$

$\mathrm{R}^{1}=\mathrm{R}^{2}=\mathrm{H}, \mathrm{R}^{3}=\mathrm{NC}$
$\mathrm{R}^{1}=\mathrm{R}^{3}=\mathrm{H}, \mathrm{R}^{2}=\mathrm{NC}$

Figura 3 - Isocianetos como produtos naturais de microorganismos (xantocilina, tricoviridina, hapalindolo A), e de esponjas (adociano, caliinolos e pupuqueananos). 
isonitrílico constitui um aspecto do maior interesse. Nas esponjas, os isonitrilos são muitas vezes acompanhados por compostos análogos que apresentam um grupo formamida ou isotiocianato em vez do isocianeto. O químico prepara os isonitrilos por desidratação de formamidas, mas a natureza trabalha em meio aquoso, e por isso não deve recorrer a esta via. Por marcação de cianeto $\operatorname{com}{ }^{13} \mathrm{C}$ e ${ }^{15} \mathrm{~N}$, foi possivel demonstrar que aquele grupo, na íntegra (como $\left.\mathrm{CN}^{-}\right)$, é incorporado no isonitrilo [19], a as formamidas e os isotiocianatos surgem da sua hidrólise e reacção com compostos sulfurados. Uma explicação para a formação primária de isocianeto seria a reacção de cianeto, como nucleófilo, com um carbocatião formado de um precursor terpénico, provavelmente uma olefina. No caso dos caliinolos e de alguns outros isonitrilos, são conhecidos derivados halogenados, e pode imaginar-se a formação do isocianeto por substituição de uma halogeneto por cianeto, com o carbocatião como intermediário, tal como na síntese clássica de Gautier. Porém, existe uma diferença fundamental entre a síntese biológica e a laboratorial, dado que a natureza produz os isonitrilos de um modo selectivo (nunca foram detectados nitrilos, como na síntese de Gautier) e ainda estereoselectivamente (com centros de quiralidade no local do ataque nucleófilo do cianeto). Estas observações indicam que o cianeto provavelmente não reage na forma livre, mas ligado a enzimas, que ainda são completamente desconhecidas.

O efeito tóxico ou repelente dos isonitrilos naturais em relação aos animais poderia ser um indício da sua provável actividade farmacológica no homem. De facto, muitos isonitrilos de origem marítima têm actividade antimicrobiana ou antibiótica, e alguns também acção antelmíntica e antiviral [16]. Além disso, foram sintetizados muitos derivados de isonitrilos naturais, com variações estruturais, que manifestam aç̧ão microbicida e antifúngica, tais como produtos com o isonitrilo conjugado a uma ligação dupla [14]. Um caso

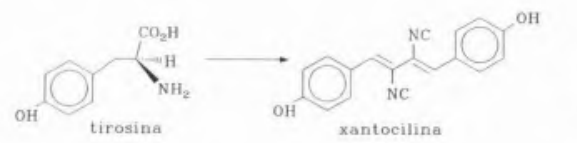

Mais adiante (secção 5) serão referidas diversas aplicações de isocianetos na síntese de compostos orgânicos de interesse farmacológico.

É ainda digna de menção uma
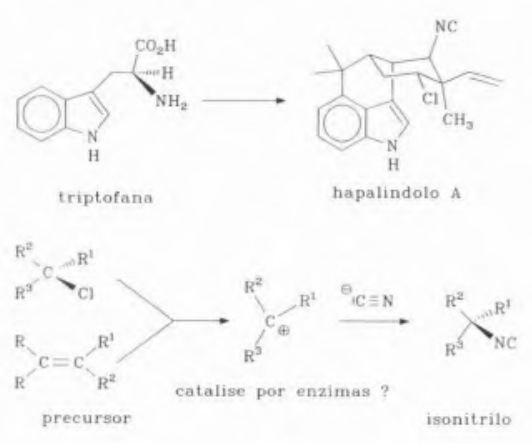

Figura 4 - Biossíntese de isocianetos a partir de aminoácidos ou de precursores terpénicos, possivelmente envolvendo a reaç̧ão de carbocatiỗes com cianeto, catalisada por enzimas.

especial é constituído por análogos de nucleósidos com grupos isonitríli$\cos$, dos quais se esperava uma actividade anti-retroviral, utilizável como medicamentos contra o SIDA. Assim, foram sintetizados derivados da timidina $[21,22,23]$ e da uridina [23], mas nenhum dos compostos mostrou actividade anti-HIV suficiente para aplicação. Novas tentativas no sector farmacêutico utilizam derivados da citosina, designadamente o NCDAC, como agentes anti-cancerígenos [24], mas somente foi detectada uma actividade moderada contra o cancro do pulmão.

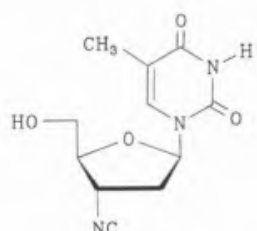

3'-isociano-3'-deoxitimidina

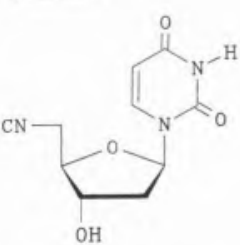

$5^{\prime}$-isociano-2', $5^{\prime}-$ dideoxiuridina

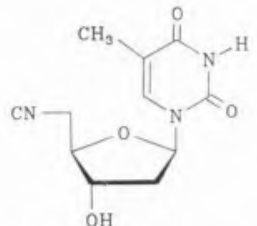

$\mathrm{OH}$

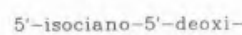
timidina

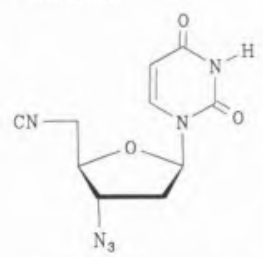

3'-azido-5'-isociano$2^{\prime}, 3^{\prime}, 5^{\prime}$-trideoxiuridin

\section{3 - ISOCIANETOS COMO SUBSTRATOS DA NITROGENASE}

Os isocianetos são reconhecidos substratos (e inibidores) da nitrogenase, a enzima fixadora de azoto. Assim, o isocianeto de metilo ( $\mathrm{C} \equiv \mathrm{NMe})$ é reduzido a dimetilamina, segundo uma via envolvendo 4-elec-

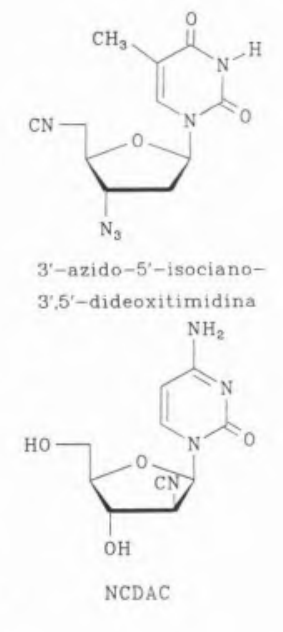

Figura 5 - Derivados de nucleósidos com grupo isocianeto, com actividade antiviral e anticancerosa. 
trões e 4-protões (equação 7), ou a metilamina e metano (além de pequenas quantidades de hidrocarbonetos mais pesados, em $\mathrm{C}_{2}$ ou $\mathrm{C}_{3}$ ), segundo uma via global hexa-electrónica e hexa-protónica (equação 8) que envolve a ruptura completa da ligação $\mathrm{CN}$ do grupo isocianeto [27].

O cianeto apresenta um comportamento comparável, sendo reduzido a metilamina (4-electrões) (equação 9), ou a metano e amoníaco (6-electrões) (equação 10); além disso, a detecção deste produto em quantidade superior à prevista pela estequeometria da reacção 10 (razão 1:1 entre $\mathrm{NH}_{3}$ e $\mathrm{CH}_{4}$ ) sugere a possibilidade de formação adicional de $\mathrm{NH}_{3}$ segundo um processo di-electrónico, possivelmente envolvendo metilenoimina $\left(\mathrm{H}_{2} \mathrm{C}=\mathrm{NH}\right)$, postulada como espécie intermediária a qual, por hidrólise, formaria amoníaco e formaldeído (equação 11) [27]. Dado que o cianeto $\left(\mathrm{CN}^{-}\right)$e o cianeto de hidrogénio $(\mathrm{HCN})$ co-existem em solução a pH 7, não foi ainda reconhecida qual destas espécies constitui o verdadeiro substrato enzimático [28], pelo que, neste contexto, a designação de "cianeto" pretende indicar qualquer destas formas (ou ambas) redutível pela enzima.

Estas reacções, sobretudo as que envolvem, na globalidade, processos hexa-electrónicos, apresentam analogias significativas com a redução enzimática, vital, do diazoto (equação 12) a qual conduz à ruptura completa da ligação tripla com for- mação de amoníaco. A nitrogenase reduz ainda outros substratos, tais como, alcinos terminais a olefinas, aleno a propeno, ciclopropeno a propano, azida a hidrazina e amoníaco, etc.

Os mecanismos de todas estas reacções enzimáticas são ainda desconhecidos, mas admite-se que envolvem a activação do substrato por coordenação ao centro activo da enzima, o qual parece ser constituído (na nitrogenase de molibdénio) por um aglomerado polinuclear com a composição $\left\{\mathrm{Fe}_{7} \mathrm{~S}_{9} \mathrm{Mo}\right.$ (homocitrato)\}, existente no cofactor (FeMoco) e cuja estrutura foi recentemente determinada por difracção de raios-X [29]. Em concordância com esta hipótese, foi já demonstrada a capacidade de coordenação, ao FeMoco isolado, do cianeto de metilo [30] e do "cianeto" [28]. Além disso, tem vindo a ser investigada a activação de diversos substratos, por centros metálicos com capacidade de coordenação de diazoto, e desenvolvida uma química de coordenação daquelas espécies [31-35], em particular isocianetos [31-33], com significado biológico e capaz de mimetizar, em certa medida (embora ainda limitada), a acção enzimática, aspectos a discutir nas secções seguintes.

Note-se ainda que, além da nitrogenase de molibdénio, foram descobertas formas enzimáticas alternativas em que este metal é substituído pelo vanádio ou, possivelmente, pelo ferro [36].

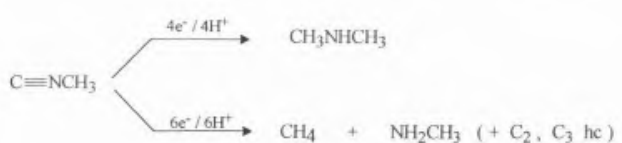

(7)

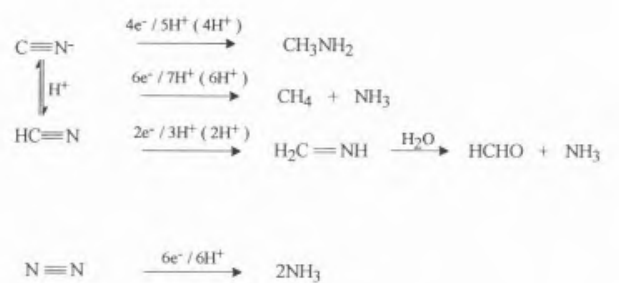

Figura 6 - Redução enzimática (pela nitrogenase) de isocianeto de metilo $\left(\mathrm{CNCH}_{3}\right)$, de cianeto $\left(\mathrm{CN}^{-}\right)$e de diazoto $\left(\mathrm{N}_{2}\right)$.

\section{4 - QUÍMICA DE COORDENAÇÃO DE ISOCIANETOS, COM SIGNIFICADO BIOLÓGICO}

\section{1 - Coordenação}

Os centros metálicos conhecidos com capacidade de coordenação de diazoto, pelo menos em complexos de estabilidade considerável, apresentam uma riqueza electrónica elevada, com o metal num baixo estado de oxidação. O diazoto constitui, em geral, um ligando lábil podendo ser substituído, e.g., por um isocianeto o qual exibe então, em espectroscopia de radiação infravermelha, um valor da frequência de extensão da vibração $\mathrm{C} \equiv \mathrm{N}, v(\mathrm{CN})$, muito inferior ao observado no estado livre, e uma geometria dobrada no átomo de azoto, podendo, assim, ser representado, com contribuição considerável, pela forma de ligação de valência (c) em vez da mais usual (d) de geometria linear que é a apresentada tipicamente em centros de baixa riqueza electrónica.

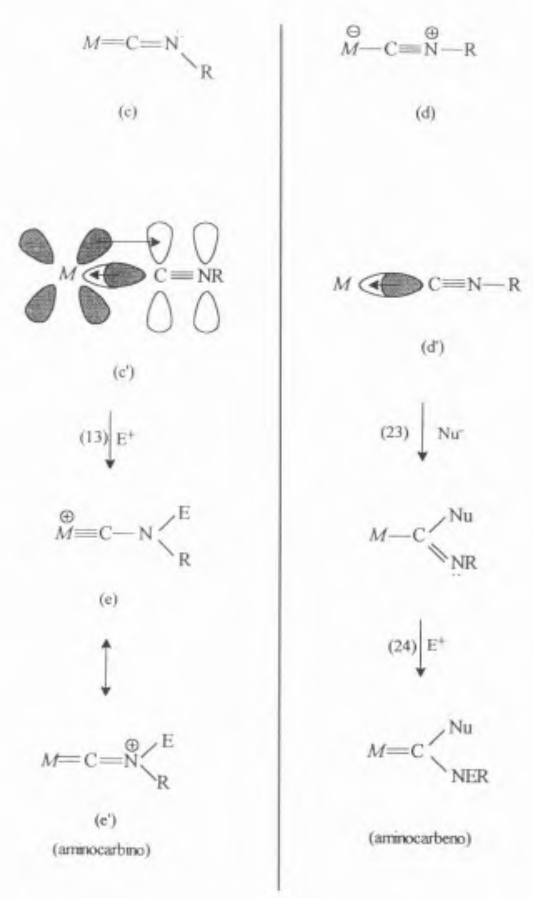

Figura 7 - Activação, por coordenação, de isocianeto a um centro metálico $(M)$ de elevada (c) ou de fraca (d) riqueza electrónica. 

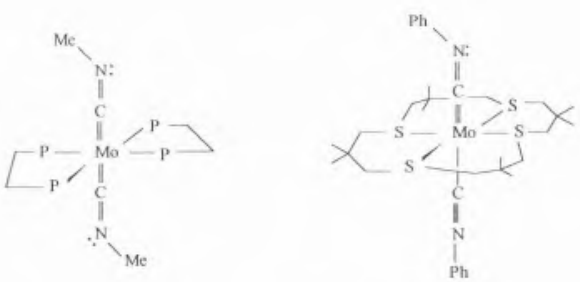

trans-[Mol(CNMe) $\left.(\mathrm{dppe})_{2}\right]$ [37]

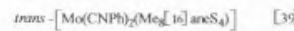

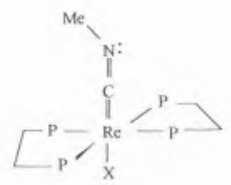

inans-[ReX(CNMeXdppeh] (X-ClouH) [38]

Figura 8 - Representação esquemática das estruturas moleculares de complexos de isocianetos dobrados.

A geometria dobrada foi já reconhecida por análise de difracção de raios-X dos complexos fosfínicos trans $-\left[\mathrm{Mo}(\mathrm{CNMe})_{2}(\mathrm{dppe})_{2}\right](\mathrm{dppe}=$ $\mathrm{Ph}_{2} \mathrm{PCH}_{2} \mathrm{CH}_{2} \mathrm{PPh}_{2}$ ) [37] e trans[ReX(CNMe) (dppe) $)_{2}$ ] $(\mathrm{X}=\mathrm{Cl}$ ou $\mathrm{H})$ [38], bem como do complexo com um tioéter em coroa tetradentado trans- $\left[\mathrm{Mo}(\mathrm{CNPh})_{2}\left(\mathrm{Me}_{8}[16] \mathrm{aneS}_{4}\right)\right]$

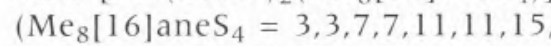
15-octametil-1, 5,9,13-tetratiaciclohexadecano) [39].

A dobra do ligando isonitrilo nestes complexos é de origem electrónica (não imposta por factores estereoquímicos), resultando de uma efectiva retrodoação electrónica $\pi$ do metal electronicamente rico para uma orbital $\mathrm{CN}$ antiligante do isonitrilo $\left(\mathrm{C} \equiv \mathrm{N} \pi^{*}\right)\left(\mathrm{C}^{\prime}\right)$. Ocorre assim um enfraquecimento da ligação $\mathrm{C} \equiv \mathrm{N}$ do isonitrilo e um concomitante fortalecimento da ligação metal-carbono (que então apresenta um carácter duplo, tipo carbénico, $\mathrm{M}=\mathrm{C}$ ), além da localização de carga electrónica no átomo de azoto (c). Os dados estruturais e espectroscópicos comprovam estas previsões que são ainda susceptíveis de racionalização por cálculos teóricos estendidos de Hückel [40] e por diagramas simplificados de orbitais moleculares $\pi[41]$.

\section{2 - Reactividade}

Entre estes complexos isonitrílicos com centros de coordenação de $\mathrm{N}_{2}$, aquele que apresenta uma maior semelhança com o centro metálico enzimático é o que contém o ligando macrocíclico sulfurado, exibindo assim um centro do tipo $\left\{\mathrm{MoS}_{4}\right\}$. Porém, talvez devido à sua fraca estabilidade, desconhece-se a sua reactividade. Em contraste, para os restantes complexos, fosfínicos, foi já desenvolvida uma química de assinalável riqueza [31-33]. Assim, o isocianeto é activado pelo centro metálico electronicamente rico $(\underline{M})$ a ataque por electrófilo $\left(\mathrm{E}^{+}=\mathrm{H}^{+}[37,42-45]\right.$, carbocatião [46], ácido de Lewis [40b], etc.), o qual ocorre no átomo de azoto (em concordância com as considerações acima tecidas) (equação 13), formando espécies de tipo aminocarbino as quais, tal como indicado por estudos espectroscópicos ou de difracção de raios-X [43, 44], podem ser representadas como híbridos de formas de ressonância com ligação metal-carbono de natureza tripla ou dupla, isto é, a forma carbínica $[\mathrm{M} \equiv \mathrm{CNER}]^{+}$(e) ou a carbénica $\underline{\mathrm{M}}=\mathrm{C}=\mathrm{NER}\left(\mathrm{e}^{\prime}\right)$ respectivamente.

Estas reacções corresporideram a um novo tipo de activação de isocianetos, sem precedente, e constitui- ram uma nova via sintética de complexos com ligações múltiplas metalcarbono (carbinos ou carbenos), um domínio de interesse actual em química organometálica [31].

Como exemplos, podem citar-se as reacções de protonação de trans $\left[\mathrm{M}(\mathrm{CNMe})_{2}(\text { dppe })_{2}\right](\mathrm{M}=\mathrm{Mo}$ or $\mathrm{W})$ com formação dos complexos de aminocarbinos trans-[M(CNHMe) (CNMe) (dppe $\left.)_{2}\right]^{+}($equação 14), os quais, por protonação subsequente, geram os compostos de tipo di(aminocarbino) trans- $\left[\mathrm{M}(\mathrm{CNHMe})_{2}(\text { dppe })_{2}\right]^{2+}$ (equação 15) [42, 43]. Nestes produtos, os dois ligandos aminocarbinos são susceptíveis de acoplamento C-C (promovido por ataque nucleófilo pelo anião do ácido usado, $\mathrm{X}^{-}$), com formação de (diamino)acetileno, trans $-\left[\mathrm{MX}\left(\eta^{2}-\mathrm{MeHNC} \equiv \mathrm{CNHMe}\right)\right.$ $\left.(\text { dppe })_{2}\right]^{+}\left(\mathrm{X}=\mathrm{F}, \mathrm{Cl}\right.$ ou $\left.\mathrm{ClO}_{4}\right)$ (equação 16) [47]. Este tipo de reacção, de acoplamento prótico de isocianetos, é de significado potencial no domínio do aproveitamento sintético de moléculas $C_{1}$, e foi reconhecido por outros autores [48] em outros sistemas e estendido para o monóxido de carbono. A ruptura da ligação $\mathrm{C} \equiv \mathrm{C}$ do (diamino)acetileno ocorre por reacção com base ou por redução, regenerando o complexo inicial diisonitrílico (equação 17) [47].

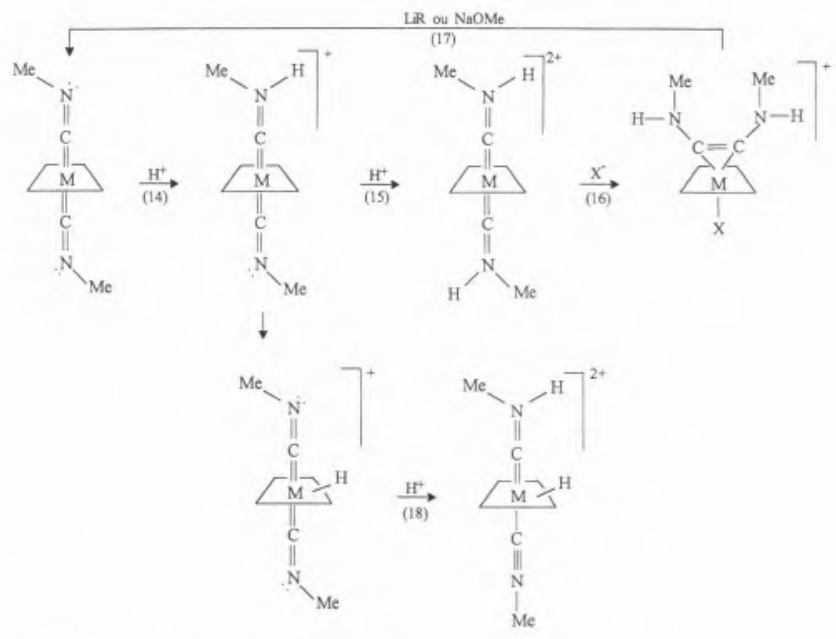

$\left.\left.\Gamma_{\mathrm{M}}^{\mathrm{M}}\right]=\mathrm{M}_{\mathrm{dppe}}\right)_{2} ; \mathrm{M}=\mathrm{Mo}$ ou $\mathrm{W} ; \mathrm{X}=\mathrm{F} ; \mathrm{Cr}^{-\mathrm{CO}_{4}}$ 
Os complexos mono(aminocarbínicos) trans-[M(CNHMe) $\left.(\mathrm{CNMe})(\text { dppe })_{2}\right]^{+}$ são instáveis e, na ausência de ácido, i.e., sem possibilidade de formação dos di(aminocarbinos) já referidos, ocorre migração protónica do aminocarbino para o metal convertendo-se nos complexos hidretos $\left.\left[\mathrm{MH}(\mathrm{CNMe})_{2} \text { (dppe) }\right)_{2}\right]^{+}[43]$, os quais, por protonação subsequente, geram os hidreto-aminocarbinos [MH(CNHMe) (CNMe) (dppe) $\left.{ }_{2}\right]^{2+}$ (equação 18) [43,49], que apresentam simultaneamente o metal e um isocianeto protonados.

Nos complexos de rénio trans$\left[\mathrm{ReCl}(\mathrm{CNR})\left(\right.\right.$ dppe $\left._{2}\right](\mathrm{R}=\mathrm{H}$, alquilo ou arilo), o isocianeto é também susceptível de adição prótica com formação do aminocarbino correspondente trans- $\left[\operatorname{ReCl}(\mathrm{CNHR})(\mathrm{dppe})_{2}\right]^{+}$ (equação 19) [44, 45].

$\mathrm{O}$ aminocarbino mais simples, $\mathrm{CNH}_{2}$, pode ser preparado não só por protonação do ligando $\mathrm{CNH}$ como ainda a partir do isocianeto $\mathrm{CNSiMe}_{3}$, por reacção de $\mathrm{HBF}_{4}$ com trans$\left.\left[\mathrm{ReCl}\left(\mathrm{CNSiMe}_{3}\right) \text { (dppe) }\right)_{2}\right]$ envolvendo a ruptura da ligação $\mathrm{N}-\mathrm{Si}$ (equação 20) [45]; o mesmo isocianeto serve de matéria prima na síntese do isocianeto de hidrogénio, $\mathrm{CNH}$, por reacção com MeOH, com formação de trans- $\left[\operatorname{ReCl}(\mathrm{CNH})(\text { dppe })_{2}\right]$ (equação 21) [45].
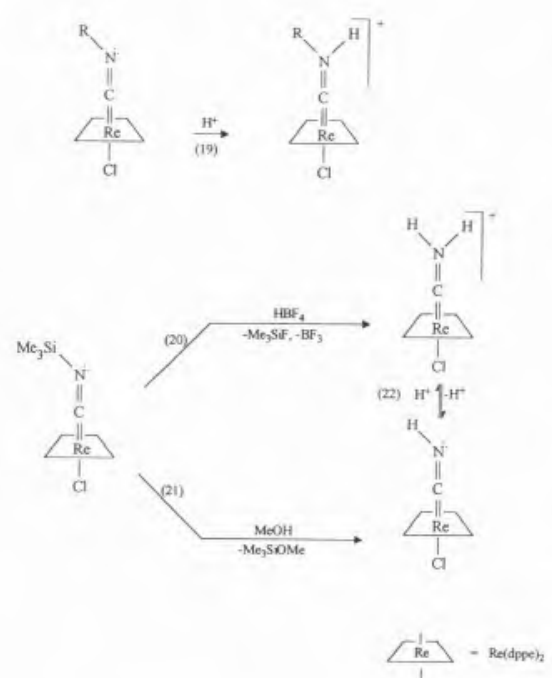

Figura 10 - Protonação de isocianetos a aminocarbinos em centro de rénio, e geração das formas mais simples

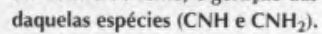

As duas espécies $\mathrm{CNH}$ e $\mathrm{CNH}_{2}$ são assim geradas num centro metálico que as estabiliza por coordenação. São interconvertíveis, quer por simples reacção de ácido/base (equação 22) [45] quer por via electroquímica (conversão induzida por transferência electrónica) [50], existem ambas no espaço interestelar [25. 51] aonde se acredita que a segunda $\left(\mathrm{CNH}_{2}\right)$ constitui um precursor importante na síntese da primeira $(\mathrm{CNH})$ ou do seu isómero $(\mathrm{NCH})$. Compreende-se, assim, que a química iónica em fase gasosa destas espécies tenha constituído objecto de atenção assinalável [51c], e recentemente recrudesceu o interesse no desenvolvimento [52] de uma química organometálica baseada no cianeto de hidrogénio.

As reacções de protonação dos isocianetos acima descritas, de ocorrência em centros metálicos activadores com alta riqueza electrónica, contrastam com o tipo tradicional, oposto, de activação daquelas espécies quando coordenadas a um centro metálico de relativamente baixa riqueza electrónica, sendo então susceptíveis de ataque nucleófilo $\left(\mathrm{Nu}^{-}\right)$ com formação de espécies de tipo imino, $\mathrm{M}-\mathrm{C}(\mathrm{Nu})=\mathrm{NR}$ (equação 23), que, por adição electrófila $\left(\mathrm{E}^{+}\right)$, formam aminocarbenos, $\underline{M}=\mathrm{C}(\mathrm{Nu})=\mathrm{NER}$ (equação 24) [53-56]. Na coordenação dos isocianetos a estes centros metálicos a componente de retrodoação $\pi$ electrónica é desprezável, predominando a doação $\sigma$ para o metal do par electrónico do carbono coordenante [formas (d) e (d')], do que resulta a activação deste átomo a ataque por nucleófilo.

\section{3 - Redução a produtos enzimáticos. Modelos}

Se os sistemas de alta riqueza electrónica de Mo, W ou Re, dos tipos acima referidos, apresentarem ligandos lábeis (fosfinas ou fosfitos monodentados) em vez das difosfinas quelantes, é possivel a ocorrência de protonação mais extensa dos isocianetos, para além do nível dos aminocarbinos, com formação de amina, amoníaco e hidrocarbonetos [57, 58]. Assim, de- signadamente, por protonação (pela acção de metanol, $\mathrm{HCl}, \mathrm{H}_{2} \mathrm{SO}_{4}$, etc.) de trans-[Mo $\left.(\mathrm{CNMe})_{2}\left(\mathrm{PMe}_{2} \mathrm{Ph}\right)_{4}\right]$, mer-[W(CNMe $\left.)_{3}\left(\mathrm{PMe}_{2} \mathrm{Ph}\right)_{3}\right]$ [57] ou mer- $\left[\operatorname{ReCl}\left(\mathrm{N}_{2}\right)(\mathrm{CNR})\left\{\mathrm{P}(\mathrm{OMe})_{3}\right\}_{3}\right](\mathrm{R}=$ alquilo ou arilo) [58], obtêm-se aqueles produtos, que incluem os detectados na acção da nitrogenase a qual reduz CNMe a metilamina, metano e vestígios de etileno e etano. A obtenção destes hidrocarbonetos $C_{2}$ envolve a formação de ligações C-C a qual, entre outras hipóteses, poderá talvez resultar de um acoplamento de isocianetos por via prótica do tipo acima referido.

Além disso, com base nos complexos aminocarbínicos e hidretoaminocarbínicos isolados nos sistemas electronicamente ricos já mencionados, e por analogia com a química de coordenação do diazoto [35, 59] desenvolvida em centros metálicos relacionáveis, é possível propor [33] a sequência reaccional indicada na figura 11 para a redução de um isocianeto a amina e metano, que constituem os produtos fundamentais gerados pela nitrogenase.

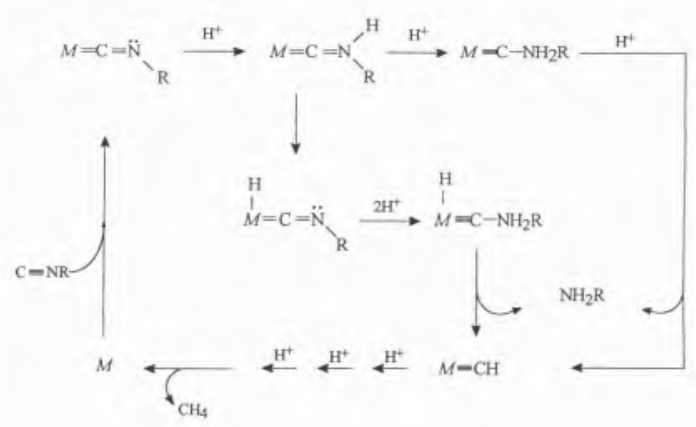

\footnotetext{
Figura 11 - Sequência reaccional proposta para a redução de isocianeto a produtos enzimáticos em centro metálico electronicamente rico (sem indicação dos passos de transferência electrónica).,
}

Este esquema assenta na capacidade do centro metálico em activar o substrato a ataque electrófilo, e na tendência daquele em formar ligações múltiplas ao átomo de carbono coordenante, com o concomitante enfraquecimento (até à ruptura) da ligação $\mathrm{C} \equiv \mathrm{N}$ do isocianeto. Se estendida ao sistema enzimático, esta hipótese deverá ainda envolver o acoplamento, às reacções de protona- 
ção, de passos redutivos de transferência electrónica, de modo a que o centro metálico mantenha o seu poder activador (redutor) do substrato e derivados. Sem o envolvimento de um agente redutor externo, o metal perderia a sua capacidade redutora após um ciclo completo, com a perda dos seus 6 electrões de valência utilizados na redução de uma molécula do substrato (equação 8).

Sob esta perspectiva, seria particularmente promissora a via electroquímica de redução dos isocianetos, a qual, com efeito, foi aplicada com considerável sucesso em algumas situações. Assim, por electrólise a potencial controlado na onda catódica de trans $-\left[\mathrm{FeH}(\mathrm{CNMe})(\mathrm{dppe})_{2}\right]^{+}$na presença de fenol como fonte protónica, detectou-se a redução do ligando CNMe a dimetilamina (equação 7) [60]; observou-se também a redução electroquímica do mesmo isocianeto na presença de aglomerados polinucleares electro-sintetizados, do tipo do cubano duplo $\left[\mathrm{Mo}_{2} \mathrm{Fe}_{6} \mathrm{~S}_{8}(\mathrm{SPh})_{9}\right]^{5}$ [61], bem como de derivados do tetratiomolibdato [62].

Convém, no entanto, esclarecer que estes modelos da acção enzimática não excluem a hipótese do envolvimento de ataque nucleófilo, do tipo tradicional, no ligando isocianeto, sendo conhecida a formação de aminas e hidrocarbonetos por ataque de hidreto a isocianeto activado por coordenação a um centro metálico de baixa riqueza electrónica [53, 63].

\section{5 - APLICAÇÃO EM SÍNTESE ORGÂNICA}

Considerando a estrutura do grupo isonitrílico (b), será de esperar uma reactividade particular, comparada com a de outros sistemas com ligações múltiplas. O carbono tem um par de electrões livre e formalmente uma carga negativa compensada por uma carga positiva no azoto. Apesar disso, a polaridade da ligação tripla é somente moderada, devido à alta electronegatividade do azoto com efeito oposto ao das cargas, como no caso do oxigénio no monóxido de carbono. Pode assim considerar-se que os isonitrilos são análogos isoelectrónicos do $\mathrm{CO}$, apresentando o átomo de oxigénio substituído pelo grupo R-N.

A reactividade do grupo isonitrílico com electrófilos é pois análogaá do CO; é sempre o par de electrões livre no carbono o centro reactivo com estas espécies, juntando-se depois um nucleófilo ao mesmo átomo (adição- $\alpha$ ) [12] (equação 25). Os nitrilos, que também apresentam uma ligação tripla $\mathrm{C}-\mathrm{N}$, reagem com electrófilos no azoto, adicionando em seguida o nucleófilo no carbono (adição- $\beta$, como a maioria das ligações múltiplas) (equação 26). Nucleófilos fortes, como compostos litiados, formam novas espécies organometálicas por adição- $\alpha$, que depois podem ser aplicadas na síntese de aldeídos ou cetonas [64] (equação 27). Mas este tipo de reacção com nucleófilos só é possível quando não existe qualquer hidrogénio no átomo de carbono vizinho ao grupo isonitrílico $(\mathrm{H}-\alpha)$ Em resultado do efeito aceitador electrónico deste grupo, aumenta a acidez deste hidrogénio de tal maneira que pode ser abstraído, formando-se um carbanião estabilizado pelo isonitrilo [65]. O carbanião pode ser alquilado com obtenção de novos isonitrilos, cuja hidrólise resulta na formação de aminas primárias ou aminoácidos (equação 20). Utilizando isonitrilos com um grupo cindível, como o tosilmetilisocianeto (TosMIC), é possível prolongar a cadeia de átomos de carbono de um composto carbonílico com formação do ácido ou nitrilo homólogo (equação 29) [66].

\section{1 - Síntese de Peptídeos e $\beta$-Lactamas}

Baseada no esquema geral da adição- $\alpha$, a reacção dos isonitrilos com compostos carbonílicos na presença de ácidos foi estudada por Passerini [67] que observou a formação simultânea de um éster e de uma amida (equação 30). Juntando uma amina à mistura resulta na formação de duas ligações peptídicas, através da adição- $\alpha$ de uma imina protonada e de um carboxilato ao isonitrilo, seguida de um rearranjo (equação 31). Esta reacção, chamada "condensação de quatro componentes" (4CC ou reacção de Ugi), foi explorada como método de síntese de peptídeos e antibióticos do género de $\beta$-lactamas [12].

$$
\begin{aligned}
& \mathrm{R}-\stackrel{\oplus}{\mathrm{N}} \equiv \stackrel{\ominus}{\mathrm{Ci}} \stackrel{\mathrm{E}^{\oplus}}{\longrightarrow}[\mathrm{R}-\stackrel{\oplus}{\mathrm{N}} \equiv \mathrm{C}-\mathrm{E}] \stackrel{\mathrm{Nu}^{\ominus}}{\longrightarrow} \mathrm{R}-\mathrm{N}=\mathrm{C}^{\prime} \bigcup_{\mathrm{Nu}}^{\mathrm{E}}
\end{aligned}
$$

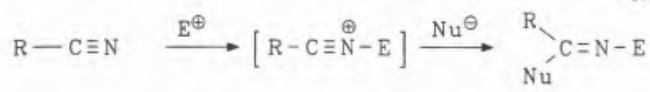

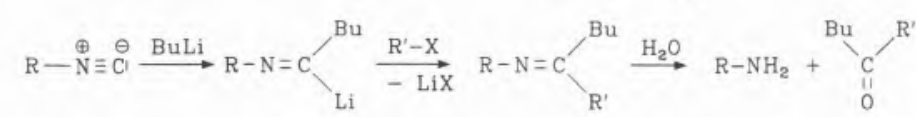

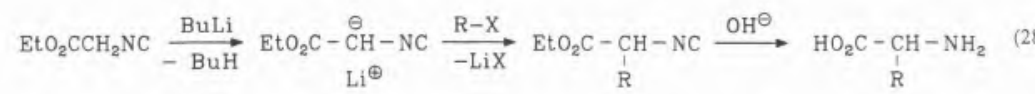

$$
\begin{aligned}
& \mathrm{CH}_{3} \bigcirc-\mathrm{SO}_{2}-\mathrm{CH}_{2}-\mathrm{NC} \stackrel{\text { base }}{\longrightarrow} \mathrm{CH}_{3} \bigcirc-\mathrm{SO}_{2}-\stackrel{\ominus}{\mathrm{CH}}-\mathrm{NC} \\
& \underset{\mathrm{H}^{\oplus}}{\stackrel{0}{\mathrm{R}^{1}-\mathrm{C}^{\prime} \mathrm{R}^{2}}} \mathrm{CH}_{3}
\end{aligned}
$$

Figura 12 - Aplicações de isocianetos em sintese orgânica. Adição- $\alpha$ a um isocianeto (25), em comparação com a adição a um cianeto (26). Síntese de compostos carbonílicos por reaç̧ão de isocianetos com reagentes organometálicos e alquilantes (27). Alquilação-a de isocianetos com bases e reagentes alquilantes, resultando na formação de aminoácidos (28). $O$ isocianeto sulfurado TosMIC permite a extensão da cadeia de átomos de carbono, com formação de ácidos ou cianetos (29), 


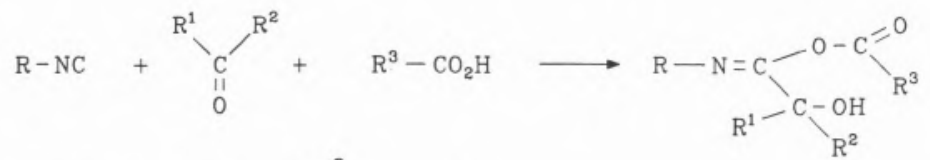

$$
\begin{aligned}
& \longrightarrow \mathrm{R}-\underset{\mathrm{H}}{\mathrm{H}}-\mathrm{C}=\mathrm{C}=\mathrm{O}-\mathrm{C}=\mathrm{O}
\end{aligned}
$$

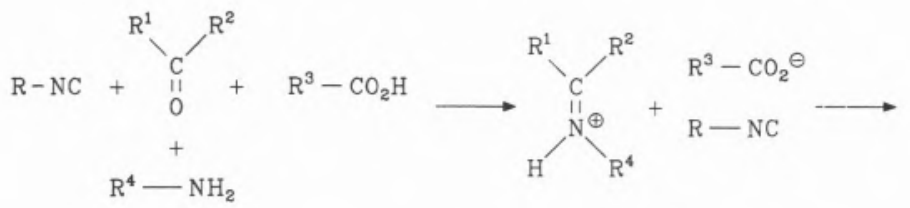

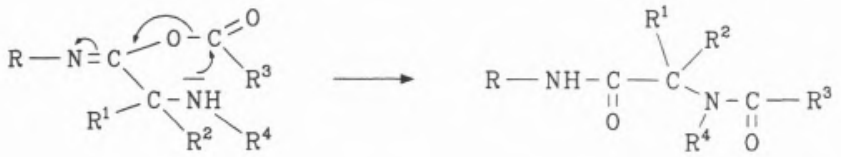

Figura 13 - Reacções de Passerini (30) e de Ugi (31), também designada "condensação de 4 componentes" (4CC), com formação de peptídeos.

Na síntese de peptídeos, é importante que estes sejam opticamente puros. Como um novo aminoácido é formado durante a reacção, cujo centro quiral resulta do átomo de carbono do composto carbonílico, é necessário recorrer a um auxiliar quiral para obtenção da actividade óptica naquela posição. Com este objectivo, foram utilizadas aminas quirais. Usando um derivado de feroceno (f), foi possível sintetizar, e.g., a tetravalina opticamente pura [68]. Os derivados de ferroceno têm não só uma acentuada capacidade de indução de quiralidade na 4CC, como também são de fácil remoção posterior por tratamento com áci- dos, para obtenção de peptídeos livres. A estereosselectividade da própria 4CC pode ainda ser aumentada durante a hidrólise com ácidos, dado que o diasteroisómero que se forma em menor quantidade reage mais rapidamente com ácido. Este passo foi designado por "estereosselectividade destrutiva" e permite a preparação de peptídeos opticamente puros. Recentemente, aminas derivadas de carbo-hidratos, como (g), mostraram um potencial sintético ainda maior [69].

Juntando a amina e o ácido carboxílico na mesma molécula, resulta uma reacção intramolecular durante a 4CC. Dos $\beta$-aminoácidos, obtêm-se assim $\beta$-lactamas, que têm um elevado interesse como antibióticos [70]. Foram desenvolvidos isonitrilos especiais, tais como (h) (k), que permitem converter o grupo carbonilo (na forma de uma amida) resultante do isonitrilo em ácido carboxílico, sem destruição do anel da $\beta$-lactama que é muito sensível às condições ácidas ou básicas [71-73]. Entre os antibióticos sintetizados por 4CC, figuram a nocardicina [74] e a tienamicina [75]. A técnica consiste em preparar um precursor, tal como um aminoácido

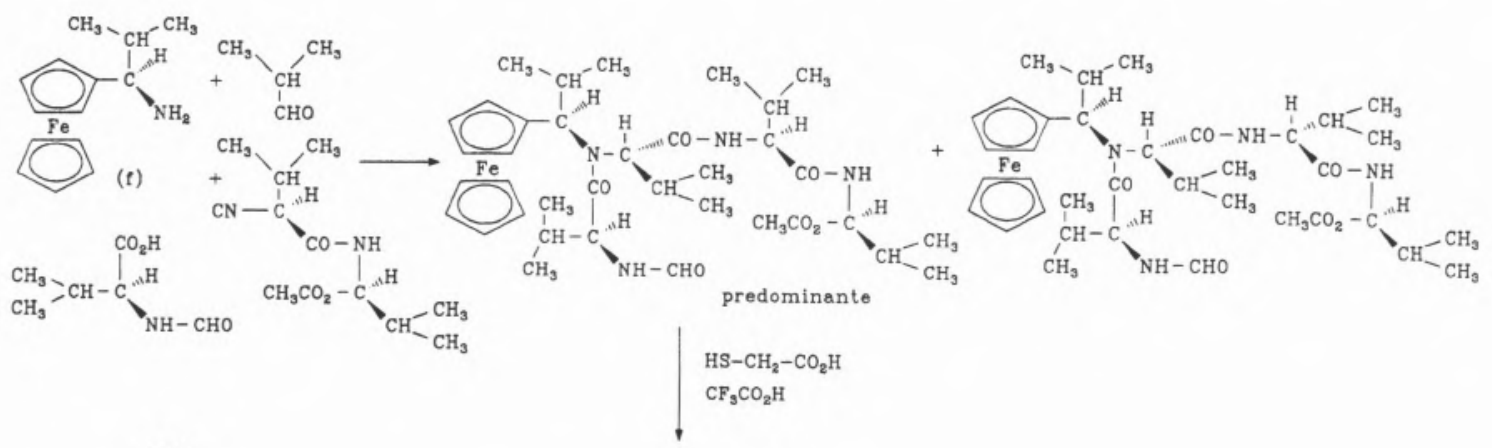

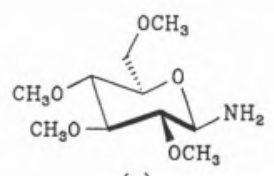

(g)

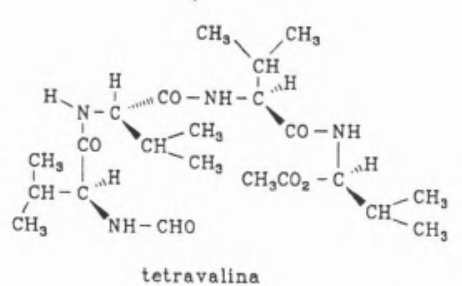




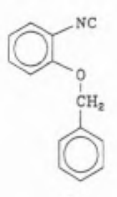

(h)

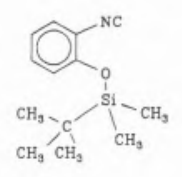

(i)

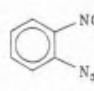

(j)

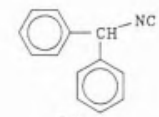

(k)
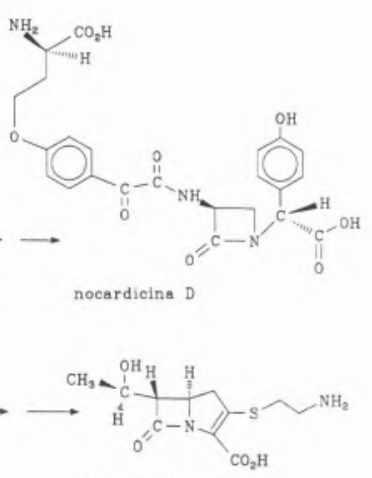

thenamicina

Figura 15 - Síntese de $\beta$-lactamas por 4CC. Os isocianetos (h)-(k) foram projectados especialmente para estas reacções, permitindo a fácil obtenção do grupo carboxílico em antibióticos tais como nocardicina e tienamicina.

substituído, que depois reage com o isonitrilo e mais um outro componente adequado.

\section{2 - Síntese de Heterociclos}

Existem métodos gerais para a síntese de heterociclos, além das blactamas, a partir de isonitrilos (para um artigo de revisão recente, veja-se [76]), designadamente por reacção com iminas (equação 32) ou por cicloadição 1,3-dipolar (equação 33) [77]. A forte tendência dos isonitrilos para a adição-a resulta na formação de anéis de 4 átomos, enquanto outras ligações múltiplas formam anéis de 5 átomos. Uma extensão da ideia básica da condensação de 4 componentes (4CC) leva ao esquema geral de reacções de muitos componentes; sem isolamento de intermediários, obtém-se um produto juntando simplesmente os seus componentes. O recorde mundial, até hoje, é a formação de somente um produto, com um bom rendimento, misturando 7 compostos (7CC) [78]. Obtém-se um único diasteroisómero de uma tiazolidina substituída (equação 34). Estas reacções de muitos componentes têm grande interesse de um ponto de vista industrial, pois envolvem poucos solventes e apenas um passo de purificação, mas, além de isonitrilos, não são conhecidos outros compostos que permitam estas reacções.
A acidez dos protões adjacentes a um grupo isocianeto pode ser explorada sinteticamente, através da formação de um carbanião estabilizado (equações 28 e 29). A reacção de um carbanião deste tipo com um composto carbonílico produz o anião de uma oxazolidina, que pode ser alquilado ou protonado $[79,80]$. Trata-se de uma síntese muito geral, aplicável à maior parte de isonitrilos e compostos carbonílicos (e.g., equação 35). Por hidrólise das oxazolidinas, obtêm-se $\beta$-aminoálcoois, uma classe de compostos de interesse farmacêutico. Porém, a produção em larga escala apresenta o problema da necessidade de uma quantidade estequiométrica de uma base forte, tal como butil-lítio ou diisopropilamida de lítio. No entanto, a descoberta de um processo catalítico para esta reacção deu novo impulso à química dos isonitrilos [81]. Como catalisadores, utilizam-se complexos de ouro com fosfinas como ligandos; recorrendo a fosfinas quirais, obtêm-se oxazolidinas quirais adequadas a aplicações farmacêuticas. Os melhores ligandos 


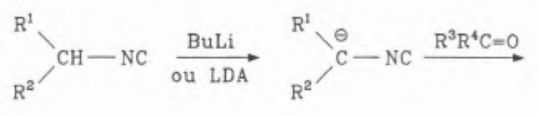
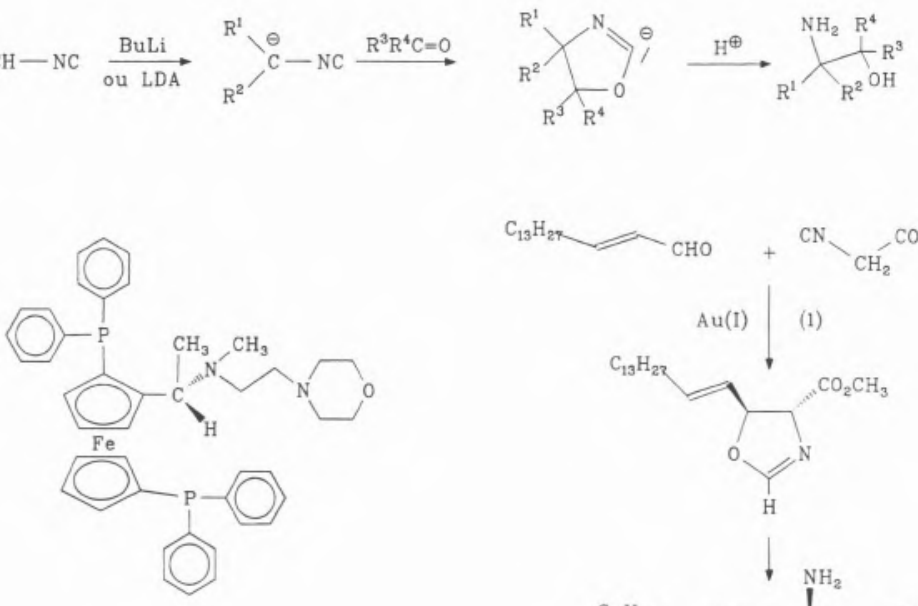

(1)

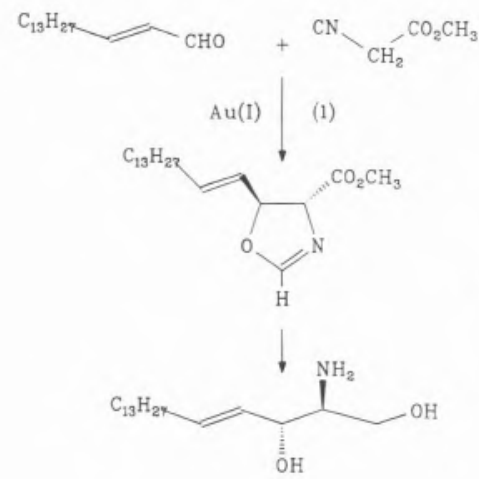

Figura 17 - Formação estequiométrica (35) e catalítica (36) de oxazolidinas e $\beta$-aminoálcoois a partir de isocianetos. A via catalítica, recorrendo a um complexo de ouro(I) com uma fosfina opticamente pura como ligando (I), derivada do ferroceno, permite obter produtos naturais estereosselectivamente.

são derivados do ferroceno, tal como (1). Estudou-se o mecanismo da reacção [82], e por esta via foram sintetizados produtos naturais [83] (equação 36).

\section{6 - APLICAÇÕES TECNOLÓGICAS}

\section{1 - Polímeros}

Além das aplicações no sector farmacêutico, a química dos isonitrilos tem outros interesses industriais, em particular com vista à obtenção de polímeros (para um artigo de revisão geral, veja-se a ref. [84]), os quais se podem agrupar em dois tipos: um que apresenta grupos isonitrílicos intactos, enquanto que o outro é obtido por reacção do grupo isonitrílico.

Os polímeros do primeiro grupo podem ser sintetizados a partir de um polímero já feito, tal como o poliestireno clorometilado (resina de Merrifield), tratando-o com o metilisocianeto litiado para substituição do cloreto pelo grupo - $\mathrm{CH}_{2} \mathrm{NC}$ [85] (equação 37). Uma outra possibilidade consiste na polimerização de isocianoalquilacrilatos [86] ou formamidoalquilacrilatos, seguida de desidratação para obtenção dos isonitrilos correspondentes [87] (equação
38). Os polímeros foram usados para a síntese de peptídeos por 4CC na fase sólida [88], e como suportes para metais de transição em catalisadores [85].

Os polímeros do segundo grupo são obtidos por polimerização do próprio grupo isonitrílico, formandose poli(iminometilenos) [89] (equação 39). Esta reacção pode ser promovida por metais de transição, particularmente níquel. Os polímeros

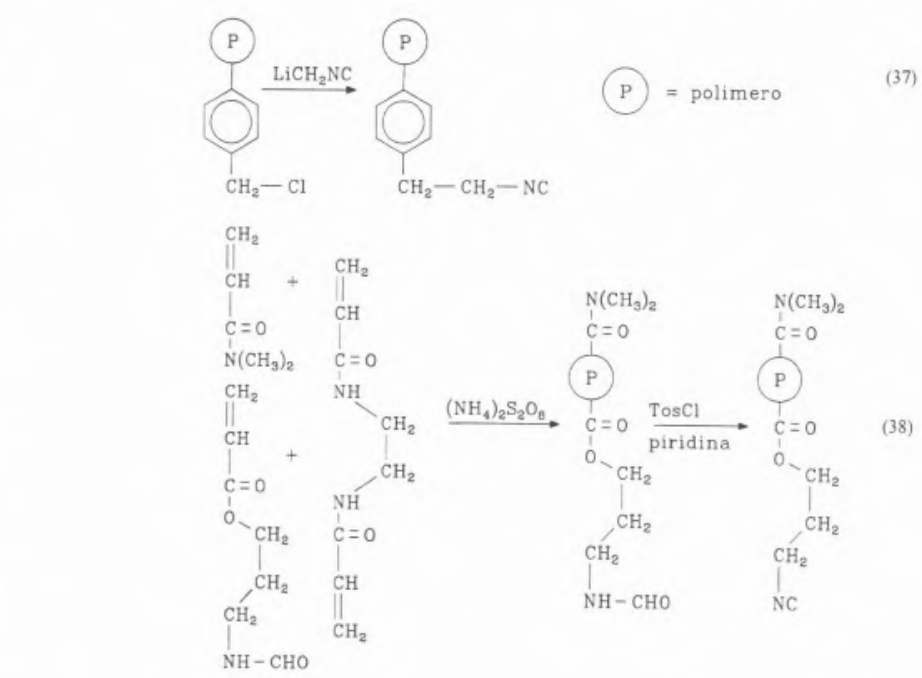

Figura 18 - Incorporação de grupos isocianetos em polímeros clorados (37), ou por copolimerização de formamidas seguida de desidratação (38). têm estruturas helicoidais, frequentemente com 4 unidades por volta, formando misturas 1:1 de hélices de sentido directo e retrógrado a partir de isonitrilos aquirais, enquanto que isonitrilos quirais formam espécies com um sentido helicoidal predominante $[89,90]$ (equação 40). Juntando um pouco de um isonitrilo quiral a um isonitrilo aquiral a polimerizar, resulta na formação preferencial de hélices quirais [91]. Utilizando um complexo de paládio com uma fosfina quiral como catalisador, foi possível obter poliquinoxalinos na forma de um enantiómero puro helicoidal a partir de diisonitrilos aquirais [92] (equação 41), cuja quiralidade é baseada somente no arranjo helicoidal no espaço, sem a presença de centros de quiralidade.

A polimerização de isonitrilos em solução resulta na formação de hélices, em resultado da auto-agregação, pelo que, quando se pretende uma outra estrutura do polímero, é necessário evitar o envolvimento de soluções. Foram então preparados isonitrilos anfifílicos com sais de amónio quaternário incorporados na molécula, que se comportam como espécies tensioactivas, formando vesículos a dispersar em água, com uma camada dupla de isonitrilos separando o interior do exterior. A po- 


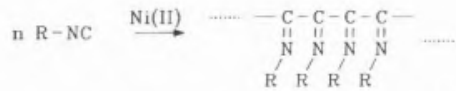

$$
\begin{aligned}
& { }_{10}{ }_{\mathrm{CH}_{3}}^{\mathrm{CH}_{3}}>\mathrm{CH}-{ }_{\mathrm{C}} \mathrm{C}_{\mathrm{NC}}^{\mathrm{CH}_{3}}
\end{aligned}
$$

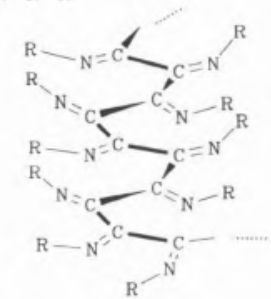

$$
\begin{aligned}
& \text { NC }
\end{aligned}
$$

Figura 19 - Polimerização de isocianetos por adição- $\alpha$ catalizada por níquel(II) (39). Isocianetos quirais resultam na formação de um enantiómero helicoida (40). Diisocianetos, com catalisadores quirais de paládio, formam poliquinoxalinos (41).

limerização é depois iniciada por um sal de níquel, ligando as moléculas e formando camadas mais rígidas e estáveis, com a conservação da forma rotunda dos vesículos [93] (equação 42). Este processo de polimerização pode ser usado para a formação de microcápsulas com diversas aplicações tecnológicas.

\section{2 - Imobilização de Enzimas}

As reacções catalíticas com enzimas apresentam frequentemente uma alta selectividade, mas dada a boa solubilidade de peptídeos ou

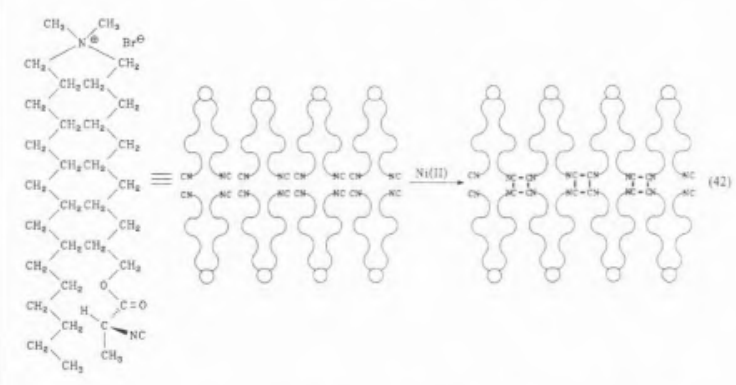

Figura 20 - Isocianetos anfifilicos com sais de amónio integrados na molécula formam vesículos com camadas duplas solúveis em água, que podem ser polimerizadas por níquel(II) (42).
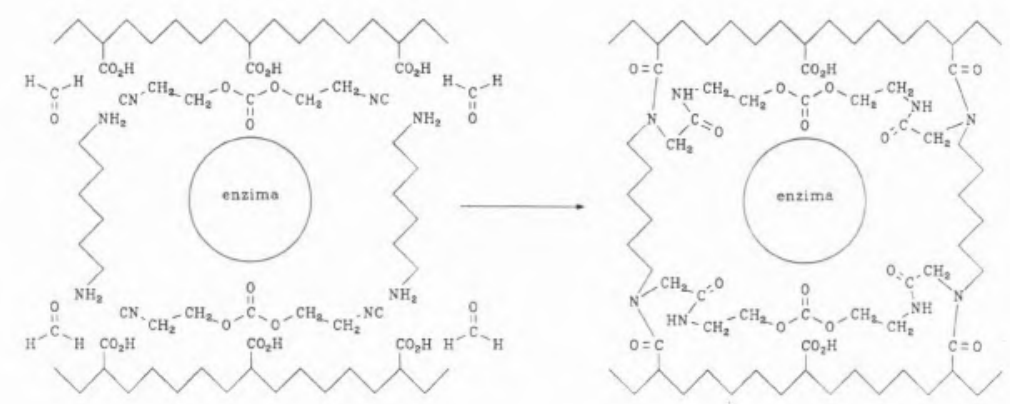

(43)

Figura 21 - Imobilização de enzimas por formação de resinas por 4CC, utilizando ácido algínico como estrutura de base (43). As enzimas conservam acentuadamente a sua actividade, dado que não reagem quimicamente, sendo apenas inseridas na resina.

proteínas em água, pode ser difícil a separação entre os produtos e o catalisador. No entanto, foram desenvolvidos métodos de fixação de enzimas em suportes, e a possibilidade de formação de peptídeos por 4CC sugeriu a aplicação desta reacção na imobilização das enzimas, que apresentem grupos $\mathrm{NH}_{2}$ e $\mathrm{CO}_{2} \mathrm{H}$ livres, capazes de reagir com isonitrilos e compostos carbonílicos [94].

O ácido algínico é um produto natural, uma glicosida polimérica de ácido $\beta$-D-manúrico e ácido $\alpha$-L-gulurónico, que ainda tem grupos carboxílicos livres, e é compatível com enzimas, não alterando a reactividade destas. Obtém-se um polímero sólido por 4CC deste ácido, formaldeído, di(isocianoetil)carbonato e diaminas (equação 43). A adição de enzimas, tal como a fosfatase ácida, á mistura dos componentes, resulta na inclusão da enzima no polímero em crescimento. Controlando o modo de adição dos componentes, é possível a obtenção de partículas rotundas com diâmetros de 0,1 até $0,5 \mathrm{~mm}$ que se podem utilizar directamente como catalisadores sólidos [95]. Apesar de estar incluída no polímero, a enzima continua a manifestar acentuada actividade catalítica $(82-87 \%)$, o que demonstra o potencial interesse industrial deste processo baseado na química de isocianetos.

\section{a Institut für Organische Chemie und Biochemie, Technische Universität München, D-85747 Garching, Germany}

bentro de Química Estrutural, Complexo I, Instituto Superior Técnico, Av. Rovisco Pais, 1096 Lisboa codex, Portugal
* Dedicado ao Professor I. Ugi, no seu $65^{\circ}$ aniversário. Uma versão resumida, em línqua espanhola, está em publicaşão na revista Investigación y Ciência.

\section{REFERÊNCIAS}

1. W. Lieke, Justus Liebigs Ann. Chem. 112 (1859) 316.

2. E. Meyer, J. prakt. Chem. [1/67 (1866) 147.

3. A. Gautier, Justus Liebigs Ann. Chem. 142 (1867) 289.

4. A.W. Hofmann, Justus Liebigs Ann. Chem. 144 (1867) 114

5. M. Meier, B. Dogan, H.-D. Beckhaus, C. Rüchardt, Nouv. J. Chim. 11 (1987) 1.

6. J.J. McBride, Jr., H.C. Beachell, J. Am. Chem. Soc. 74 (1952) 5247

7. D.E. Arnold, S. Cradock, E.A.V. Ebsworth, I.D. Murdoch, D.W.H. Rankin, D.C.J. Skea, R.K. Harris, B. J Kinnber, I. Chem. Soc. Dalton Trans. (1981) 1349.

8. M.R. Booth, S.G. Frankiss, Spectrochim. Acta A 26 (1970) 859 .

9. K. Georgiou, A.C. Legon, I. Mol. Struct. 78 (1982) 257.

10. J.A. Seckar, J.S. Thayer, Inorg. Chem. 15 (1976) 501.

11. W.P. Weber, G.W. Gokel, I.K. Ugi, Angew Chem. 84 (1972) 587

12. I. Ugi (Ed.). "Isonitrile Chemistry", Academic Press, New York 1971

13. R. Obrecht, R. Herrmann, I. Ugi, Synthesis (1985) 400. 14. I. Hagedorn, H. Tönjes, Pharmazie 12 (1957) 567.

15. P.J. Scheuer, Acc. Chem. Res. 25 (1992) 433.

16. C.W.J. Chang, P.J. Scheuer, Top. Curr. Chem. 167 (1993) 33.

17. P.J. Scheuer, Naturwissenschaften 69 (1982) 528.

18. I.E. Baldwin, H.S. Bansal, J. Chondrogianni, L.D. Field, A.A. Taha, V. Thaller, D. Brewer, A. Taylor, Tetrahedron 41 (1985) 1931.

19. P. Karuso, P.J. Scheuer, J. Org. Chem. 54 (1988) 2092. 
20. I. Hoppe, U. Schöllkopf, Liebigs Ann. Chem. (1984) 600 .

21. M. Maillard, A. Faraj, F. Frappier, J.-C-Florent, D.S Grierson, C. Monneret, Tetrahedron Lett. 30 (1989) 1955.

22. R. Karl, P. Lemmen, I. Ugi, Synthesis (1989) 718.

23. J. Hiebl, E. Zbiral, J. Balzarini, E.De Clerca, I. Med Chem. 34 (1991) 1426.

24. A. Matsuda, A. Dan, N. Minakawa, S.J. Tregear, S. Okazaki, Y. Sugimoto, T. Sasaki, J. Med. Chem. 36 (1993) 4190.

25. G.L. Blackman, R.D. Brown, P.D. Godírey, H.I. Gunn, Nature 261 (1976) 395; S. Taylor, D. Williams, Chem. Britain (1993) 680; e referências aí citadas.

26. T.L. Lee, A.P. Rendell, Chem. Phys. Lett. 177 (1991 491: M. Peric, M. Mladenovic, S.D. Peyerimhoff, R.J. Buenker, Chem. Phys. 82 (1983) 317; e referências aí citadas.

27. B.K. Burgess, in "Molybdenum Enzymes" T.G. Spiro (Ed.). Wilew, New York, Capitulo 4, 1985; e rẹerências ai citadas.

28. A.I.M. Richards, D.I. Lowe, R.L. Richards, A.I. Thomson, B.E. Smith, Biochem. 1. 297 (1994) 373.

29. J. Kim, D.C. Rees, Science 257 (1992) 1677 .

30. S.D. Conradson, B.K. Burgess, S.A. Vaughn, A.L. Roe, B. Hedman, K.O. Hodgson, R.H. Holm, I. Biol. Chem. 264 (1989) 15967.

31. A.I.L. Pombeiro, in "Transition Metal Carbvne Comple. xes", F.R. Kreissl (Ed.), NATO ASI Series, Kluwer Academic Publishers, Dordrecht, The Netherlands, (1993) 105-121.

32. A.I.L. Pombeiro, R.L. Richards, Coord. Chem. Rev, 104 (1990) 13.

33. A.J.L. Pombeiro, Memórias da Academia das Ciências de Lisboa, Classe de Ciências 23 (1980) 393.

34. A.J.L. Pombeiro, New J. Chem. 18 (1994) 163; Inorg. Chim. Acta 198-200 (1992) 179.

35. (a) R.L. Richards, in "Biology and Biochemistry of Nitrogen Fixation", M.I. Dilworth e A.R. Glenn (Eds.), Elsevier, Amsterdam, 1991, pp. 58-75; Chem. Brit. 24 (1988) 133. (b) D.J. Evans, R.A. Henderson e B.E. Smith, in "Bioinorganic Catalysis", I. Reedijk (Ed.), Marcel Dekker Inc., New York, (1993) 89-130.

36. R.R. Eady, in "Vanadium in Biological Systems", N.D. Chasteen (Ed.), Kluwer, Amsterdam, (1990) 99; R.N. Pau, in "Biology and Biochemistry of Nitrogen Fixation", M.J. Dilworth e A.R. Glenn (Eds.), Elsevier, Amsterdam, 1991.

37. J. Chatt, A.J.L. Pombeiro, R. L. Richards, G. Royston, K. Muir, R. Walker, J. Chem. Soc., Chem. Commun. (1975) 708 .

38. M.F.N.N. Carvalho, M.T. Duarte, A.M. Galvào, A.J.L. Pombeiro, 1. Organometal. Chem. 469 (1994) 79.

39. T. Adachi, N. Sasaki, T. Ueda, M. Kaminaka, T. Yoshida, 1. Chem. Soc., Chem. Commun. (1989) 1320.

40. (a) E.G. Bakalbassis, C.A. Tsipis, A.J.L. Pombeiro, I. Organometal. Chem. 408 (1991) 181; (b) M.F.N.N. Carvalho, A.J.L. Pombeiro, E.G. Bakalbassis, C.A. Tsipis, I. Organometal. Chem. 371 (1989) C26.

41. A.J.L. Pombeiro, Rev. Port, Quim. 21 (1979) 90: I. Chatt, G.J. Leigh, C.J. Pickett, A.J.L. Pombeiro, R.L. Richards, Nouv. J. Chim. 2 (1978) 541

42. J. Chatt, A.J.L. Pombeiro, R.L. Richards, J. Chem. Soc. Dalton Trans., (1980) 492.
43. A.J.L. Pombeiro, R.L. Richards, Trans. Met. Chem. 5 (1980) 55 .

44. A.J.L. Pombeiro, M.F.N.N. Carvalho, P.B. Hitchcock, R.L. Richards, J. Chem. Soc., Dalton Trans. (1981) 1629

45. A.J.L. Pombeiro, D.L. Hughes, C.J. Pickett, R.L. Richards, J. Chem. Soc., Chem. Commun. (1986) 246.

46. J. Chatt, A.J.L. Pombeiro, R.L. Richards, J. Organometal Chem. 184 (1980) 357

47. J.J.R. Fraústo da Silva, M.A. Pellinghelli, A.IL. Pombeiro, R.L. Richards, A. Tiripicchio, Y. Wang, I. Organometal. Chem. 454 (1993) C8; resultados nảo publicados.

48. C.T. Lem, P.W.R. Confield, S.J. Lippard, I. Am. Chem. Soc, 99 (1977) 617: R. N. Virtis, S. L Lippard, Isr. I Chem. 30 (1990) 331: A.C. Filippou, Polyhedron 9 (1990) 727.

49. I. Chatt, A.J.L. Pombeiro, R.L. Richards, J. Chem. Soc. Dalton Trans. (1979) 1585

50. M.A.N.D.A. Lemos, M.F.C. Guedes da Silva, A.J.L. Pombeiro, Inorg. Chim. Acta, em publicaçào

51. (a) DI. Defrees, IS Binkley, M. Frisch, A.D. McLean, I. Chem. Phys. 85 (1986) 5194 ; (b) M.P. Conrad, H. F. Schaeffer III, Nature 274 (1978) 456; (c) P.C. Burgers, I.L. Holmes, J.K. Terlouw, J. Am. Chem. Soc. $106\langle 1984$ 2762.

52. W.P. Fehlhammer, M. Fritz, Chem. Rev. 93 (1993 1243.

53. E.M. Badley, I. Chatt, R.L. Richards, I. Chem. Soc. A (1971) 21 .

54. P.M. Treichel, Adv. Organometal. Chem. 11 (1973) 21. 55. F. Bonati, G. Minghetti, Inorg. Chim. Acta 9 (1974) 95. 56. F. Singleton, Dosthuizen, Adv. Organometal. Chem. 22 (1983) 209

57. A.J.L. Pombeiro, R.L. Richards, Trans, Met, Chem, 5 (1980) 281.

58. M.F.N.N Carvalho, A.I.L. Pombeiro, U Schubert, O Orama, C.J. Pickett, R.L. Richards, I. Chem. Soc, Dalton Trans. (1985) 2079.

59. I. Chatt, I.R. Dilworth, R.L. Richards, Chem, Rev, 78 (1978) 589; I. Chatt, L.M.C. Pina, R.L. Richards (Eds.J, "New Trends in the Chemistry of Nitrogen Fixation", Academic Press, London, 1980; I.R. Dilworth, R.L. Richards, in "Comprehensive Organometallic Chemistry", G. Wilkinson, F.G. Stone, E.W. Abel (Eds.), Pergamon, 1982, Cap. 60, p. 1073 R.A. Henderson, G.J. Leigh, C.J. Pickett, Adv, Inorg. Chem. Radiochem. 27 (1983) 197.

60. L.M.D. Ribeiro, M.A.N.D. A Lemos, IJ.R. Fraústo da Silva, A.I.L. Pombeiro, Portug. Electrochim. Acta 11 (1993) 117

61. K. Tanaka, Y. Hozumi, T. Tanaka, Chem. Letters (1982) 1203; K. Tanaka, Y. Iwasaka, M. Tanaka, T. Tanaka, M. Honjo, T. Tanaka, J. Am. Chem. Soc. 104 (1982) 4258.

62. S.S.P.R. Almeida, I.J.R. Fraústo da Silva, R. Herrmann, A.I.L. Pombeiro, Portug. Electrochim. Acta 6 (1988) 135.

63. E.L. Moorhead, B.J. Weathers, E.A. Ufkes, P.R. Robinson, G.N. Schrauzer, I. Am. Chem. Soc. 99 (1977) 608\%.

64. M.P. Periasamy, H.M. Walborsky, Org Prep Proc, Int 11 (1979) 293.

65. U. Schöllkopf, F. Gerhart, Angew. Chem, 80 (1968) 842
66. O.H. Oldenziel, A.M. van Leusen, 1. Org. Chem, 42 (1977) 3114

67. M. Passerini, Gazz. Chim. Ital. 51 II (1921) 126 e 181.

68. R. Urban, D. Marquarding, I. Ugi, Hoppe-Seyler's Z Physiol. Chem. 359 (1978) 1541

69. M. Goebel, 1. Ugi, Synthesis (1991) 1095.

70. I. Ugi, Angew. Chem. 94 (1982) 826.

71. J. Geller, 1. Ugi, Chem. Scr. 22 (1983) 85.

72. R. Obrecht, S. Toure, I. Ugi, Heterocycles 21 (1984 271

73. T. El-Shihi, R. Herrmann, Z Naturforsch. 41b (1986) 132 .

74. H.P. Isenring, W. Hofheinz, Synthesis (1981) 385

75. M. Hatanaka, H. Nitta, T. Ishimaru, Tetrahedron Lett. (1981) 3883 .

76. S. Maraccini, T. Torroba, Org. Prep. Prod. Int. 25 (1993) 141

77. D. Moderhack, Synthesis (1985) 1083

78. A. Dömling, I. Ugi, Angew. Chem. 105 (1993) 647.

79. U. Schöllkopf, Angew, Chem. 89 (1977) 351.

80. U. Schöllkopf, Pure Appl. Chem. 51 (1979) 1347.

81. Y. Ito, M. Sawamura, T. Hayashi, J. Am. Chem. Soc 108 (1986) 6405 .

82. A. Togni, S.D. Pastor, I. Org, Chem, 55 (1990) 1649

83. Y. Ito, M. Sawamura, T. Hayashi, Tetrahedron Lett. 29 (1988) 239.

84. R. Arshady, M. Zecca, B. Corain, Reactive Polymers 20 (1993) 147 .

85. M. Berry, I. Csorba, R.K. Champaneria, J.S. Howell, Z. Naturforsch, 43b (1988) 862 .

86. B. Corain, M. Zecca, F. Okon Sam, S. Lora, G. Palma, A.C. Veronese, Makromol. Chem., Rapid Commun. 10 (1989) 697.

87. R. Arshady, I. Ugi, Polymer 31 (1990) 1164

88. R. Arshady, 1. Ugi, Z. Naturforsch. 36b (1981) 1202

89. A.J.M. van Beijnen, R.J.M. Nolte, W. Drenth, A.M.F. Hezemans, P.J.F.M. van de Coolwijk, Macromolecules 13 (1980) 1386

90. I.M. van der Eijk, R.I.M. Nolte, W. Drenth, A.M.F. Hezemans, Macromolecules 13 (1980) 1391.

91. P.C.J. Kramer, M.C. Cleij, R.J.M. Nolte, T. Harada, A.M.F. Hezemans, W. Drenth, I. Am. Chem. Soc 110 (1988) 1581

92. Y. Ito, Y. Kojima, M. Murakami, Tetrahedron Lett. 34 (1993) 8279 .

93. M.F.M. Roks, R.S. Dezentjé, V.E.M. Kaats-Richters, W. Drenth, A.J. Verkeii, R.I.M. Nolte, Macromolecules 20 (1987) 920.

94. C. Goldstein, A. Freeman, M. Sokolovsky, Biochem. J. $143(1974) 497$

95. S. König, I. Ugi, Z. Naturforsch. 46b (1991) 1261 